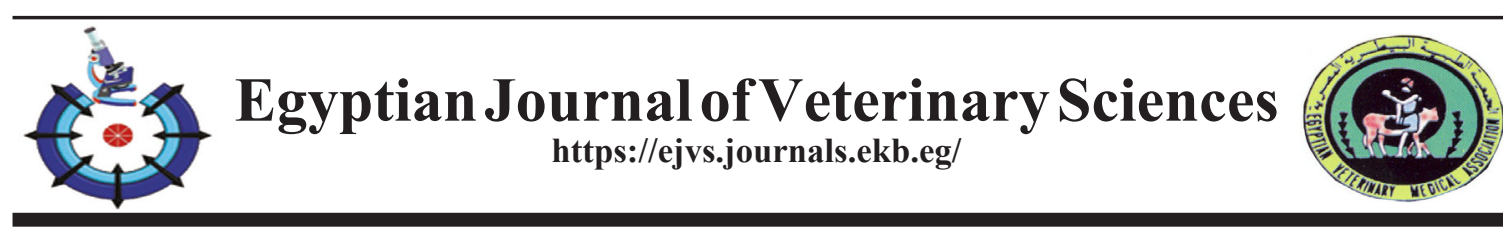

\title{
Physiological role of Nanotechnology in Animal and Poultry Nutrition: Review
}

\author{
Hadeel. M. Hameed \\ Department of Physiology, Biochemistry and Pharmacology, College of Veterinary \\ Medicine, University of Mosul, Iraq.
}

\begin{abstract}
$\mathrm{N}$ recent years, nanotechnology has gained much attention within the scientific community in many countries. Many companies specializing in the manufacture of new forms of nanomaterials have introduced poultry and livestock production systems in order to enhance the efficiency of animal production. Nano mechanism is no longer a connotation or notion for the modern scientist only, but it has overturned into a recent enabling technique over the years, with huge possible to transFig. the field of cultivation and domestic animal, so evolved in these fields can be conveyed to avian and animals offspring systems with the aim of increasing production efficiency and meeting human needs of quality poultry and animal products. As a result of the small size of nanoparticles, their passage is very fast through the walls of the gastrointestinal tract, creating many important effects in various body systems, which provides the opportunity for researchers to deal with nanomaterials by studying many veterinary fields, including production, reproduction, disease control, dealing with biological materials such as the study of DNA and cellular molecules. Objective: this article aims to shed light on the available information regarding additives based on nanoparticles and to determine the possibility and importance of using compounds and nanomaterials as feed additives in animal diets.
\end{abstract}

Keywords: Nanotechnology, Poultry, Feed additives, Production, Livestock, Physiology.

\section{Introduction}

In the field of feed additives to animal diets, many nutritional supplements have been used, including organic acids, enzymes, probiotics, and many others, and many research has explained that the use of these materials posse important positive effects to increase and improve animal production, where Hameed et al. (1) show that the use of $\beta$-mannanase, probiotic and external emulsions at a dose of $0.5 \mathrm{~g} / \mathrm{kg}$ ratio in quail diets led to an increase in production through an elevation in the level of FSH and LH hormones in the blood serum, Maty and Hassan [2] also indicated that adding organic acids to the quail diet led to raising in body mass and an increase in the level of growth hormone. However, as an outcome of the swift evolution in the field of animal production, the interest in nanotechnology has increased for use as feed supplements in animal diets, especially poultry. The expression nanoparticle is acquired from a Latin idiom mean dwarfism, the dimensions of the nanoparticles range from 1-100 nanometers [3], as a result of the characteristics of nanomaterial represented in small size its can direct this technique to find radical solutions to many veterinary problems, especially pathogens [4], and due to their strong association with antibodies, these particles can be used for diagnostic and curative purposes [5]. The continuous development of science has led to the expansion of the use of nanoparticles in the field of various veterinary research[6]. Due to the antimicrobial properties, nanoelements such as zinc, copper, and chromium nanoparticles can

Corresponding author: Hadeel.M. Hameed, E.mail: hadeel.mohammad@uomosul.edu.iq

(Received 23/04/2021; accepted 20/05/2021) 
be used as possible alternatives to feed additives instead of using antibiotics. In addition, the use of nanocomposites as feed supplements instead of larger particles reduces the excretion of metals [7], for example addition nanozinc oxide with a dose of $800 \mathrm{mg} / \mathrm{kg}$ in animal diets improves intestinal structure and daily growth rate [8].

\section{The physiological role of nanoparticles}

1 - It increases the surface area of the compounds, allowing the opportunity for biological reactions

2- Extending the stay of compounds in the digestive system, which gives a wider scope for enzymatic reactions

3- Reducing the effect of the intestinal excretion mechanism, and gives a better period for the digestion and absorption process

4- Due to their small particles, they penetrate deeply into the tissues through the tiny capillaries

5- It passes through the epithelial lining organs such as the liver

6- Effective absorption by cells

7 - Efficiency of the delivery of active compounds to the target organs in the body [3].

\section{Employment of nanotechniquein animal food}

Nanotechnique provides a wide field to veterinarians for treatment, diagnosis, tissue engineering, production of vaccines, and modern disinfectants, as it can be used in the domain of animal health, offspring, upbringing, and procreation [5]. Fig. 1. As a result of the small size of the nanoparticles, they reach the target cells more quickly, allowing the usage of very small doses, which results in reducing the residual compounds and dragging time in the tissues of livestock [4]. The produce of nanoparticles prepared many benefits for producing animal supplements with lower cost and concentrations. It can also aid control pathogens existing in the diet, regulate the rumen fermentation procedure, and outdo numerous sexual obstacles in animals [9]. Many nanoparticles are available for use commercially as feed supplements in animal food, for example, nano zinc oxide, which amelioration the growth rate, increases immunity and reproduction of livestock and poultry [10]. Rajendran et al.[11] indicated an increase in milk production in infected dairy cows with mastitis when treated with nano zinc oxide.

1. Increased mineral bioavailability

2. More retention time

3. Avoid mineral-mineral/mineral-vitamin antagonism

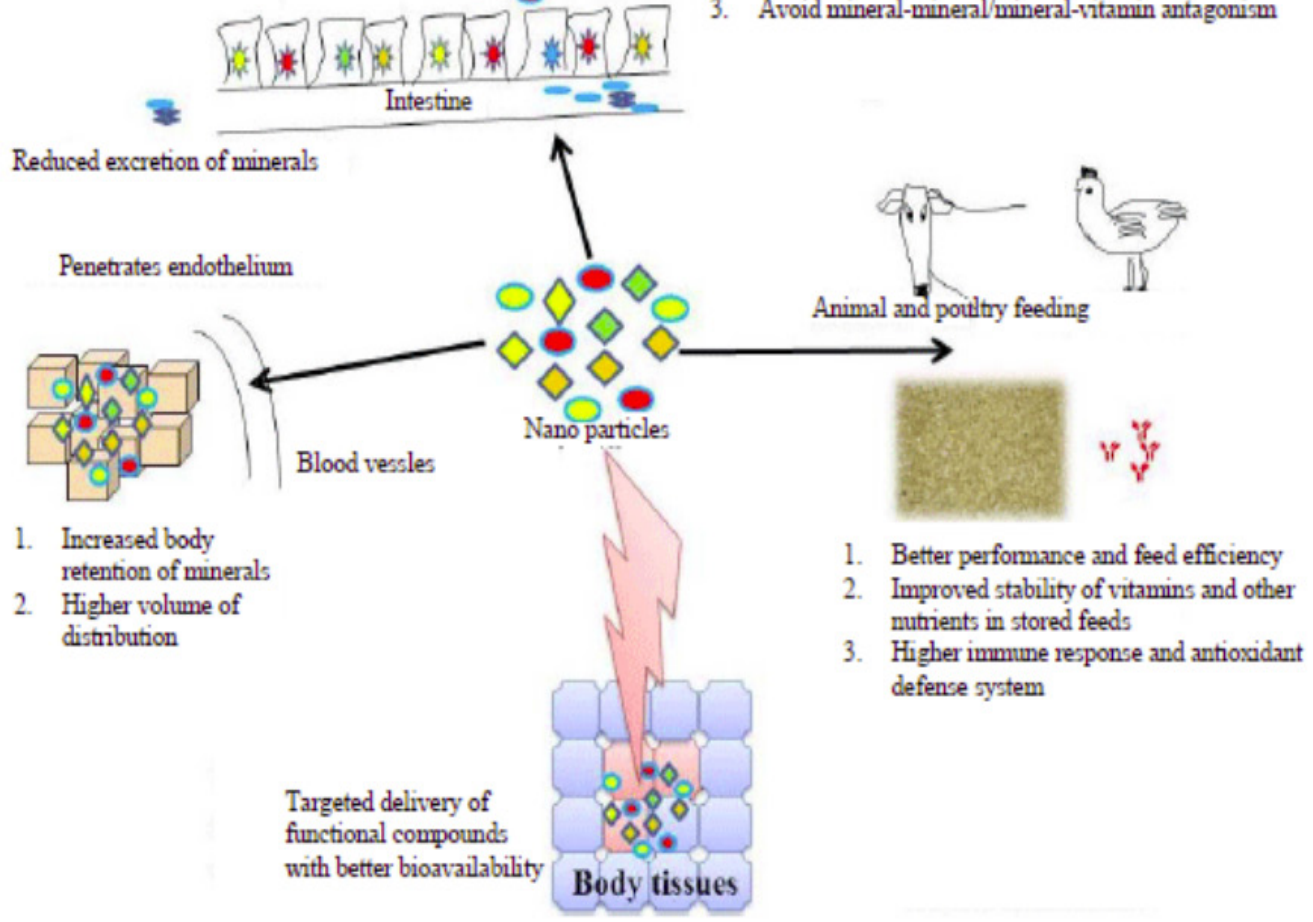

Fig. 1. Employment of nanotechnique in animal food[12].

Egypt. J. Vet. Sci. Vol. 52, No. 3 (2021) 
The role of nanocomposites in amelioration ecosystem in poultry

The effectiveness and efficiency of the intestine in poultry depends greatly on food, the intestinal mucosa is characterized by its containment of finger-like protrusions called villi that increase the surface area of absorption [13]. The internal mucosa and the villi length play a critical role in the absorption process if the villi length is directly proportional to the absorption of the digested material [14]. Several studies have indicated the importance of nanocomposites in improving the internal environment of the intestine in poultry, as Ahmadi et al.[15] indicated that the addition of nano zinc at a rate of $60 \mathrm{mg} / \mathrm{kg}$ feed to broiler diets led to an increase in villi length during the growth stage. Where the nanoparticles work to maintain the integrity of the intestinal epithelium and reduce the loss of cells [16]. The importance of nanoparticles also lies in improving the internal environment of poultry by increasing the number of goblet cells, which are characterized by the secretion of mucus, which forms a barrier that protects the intestinal walls. Sultan et al [17] indicated that the use of nanoparticles in chicken diets led to an elevated in the number of these cells. The acidic mucous secretions of these cells have a protective role for the intestinal mucosa against many pathogens and facilitate the movement of digested nutrients as a result of reducing the viscosity of these substances, which leads to an increase in the immune response of the birds [18]. These positive effects and the immune stimulation of nanoparticles are due to the smallness of its size and ability to penetrate the intestinal mucosa more easily compared to large particles. The importance of nanoparticles also lies in reducing heat stress in poultry, as Abbasi et al.[19] indicated that adding $0.5 \%$ silver nanoparticles to the broiler ratio improved the number of beneficial microbes in the gut exposed to heat stress. Fig.(2) can summarize the important role of nanomaterials in chickens.

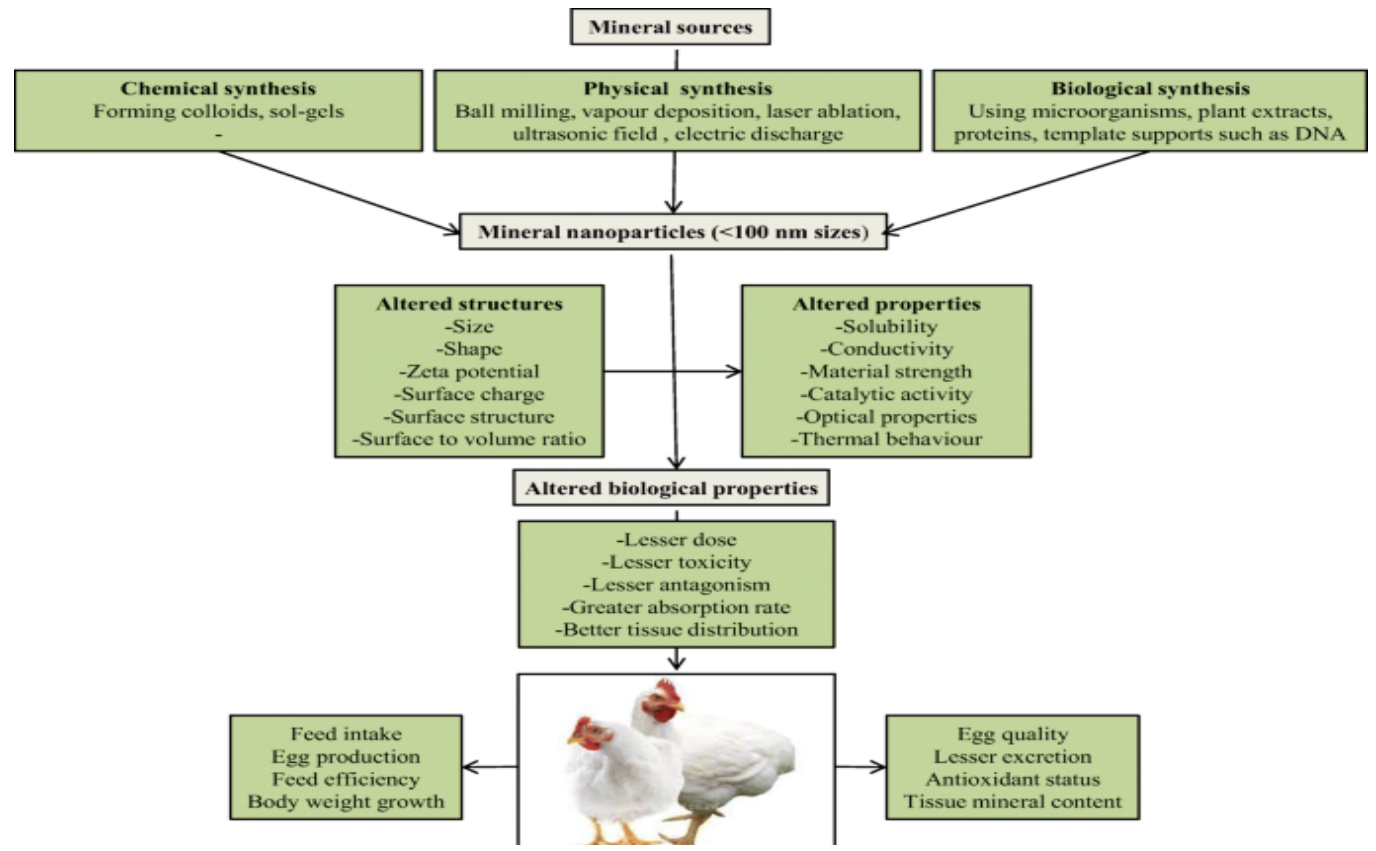

Fig. 2. Role of nanomaterials in chickens[20].

\section{The function of nanocompoundsin the ruminal fermentation}

The rumen is a complex ecosystem in which the consumed nutrients are digested anaerobically by microorganisms such as bacteria and fungi and the final product of food fermentation is VFAs, which are used by the host ruminants. The relation between the beneficial bacteria and the host animal results in an equivalent relevance that permits ruminants to digest fiber- affluent and minimal-protein materials [21]. The fermentation process in the rumen is highly inefficient because it produces some final compounds like methane and ammonia [22]. For the purpose of improving the efficiency of microbial digestion, many food systems have been followed to change the 
path of microbial digestion in a way that serves the efficiency of the digestive process without affecting the health and productivity of the animal [23], in order to achieve this goal, the employed of minerals in the diet of animals has been directed towards, including nanoscale minerals because of their importance in improving the digestion process due to their small particles and provision of a large surface area. Hassan et al.[24] indicate that the addition of nanozinc at dose 20 $\mathrm{mg} / \mathrm{kg}$ feed led to reduced methane production and improved level of antioxidants. This positive effect of nanoparticles by reducing the level of methane gas can be attributed to reducing the numbers of bacteria producing it or re-directing the hydrogen flow to bind to the receptors for producing propionate [25]. The positive effect of these minerals also lies in their improvement of some digestive enzymes in the alimentary channel [26].

The importance of nanoparticles in horse nutrition

There are many problems facing horse breeding, including digestive disorders, toxic pollutants for feed, bacterial and fungal infections [27] Therefore, the current trend has been to use nanoparticles as feed supplements in equine breeding farms instead of antibiotics because of their positive effects on control many diseases, improving the daily growth rate and the efficiency of the digestive process, the challenge of using this technique lies in the ability of its molecules to analyze many pathogens in the alimentary tract
[28]. Pathological conditions of the digestive system, especially the problem of diarrhea in foal, are among the most important obstacles to growth and have negative effects on the process of assimilation of digested material [29], where Tiwari et al.[30] indicated that the use of nano zinc at a dose of $800 \mathrm{mg} / \mathrm{kg}$ in horse diets led to a decrease in the incidence of diarrhea and a significant increase in the daily growth rate of the foal. These compounds had significant effects in inducing changes in the composition of the gut as Moyosore et al.[31] indicated that the supplement of nanoscale zinc results in a significant rise in the length, width, and surface area of villi, leading to improved digestion and absorption of nutrients. Nano food reduces gut fermentation disorders [32]. Research conducted by Saware et al.[33] indicates an increase in the effectiveness of digestive enzymes, especially the $\alpha$ - amylase when using silver and gold nanoparticles in horse food, and this explains the mechanism of the action of these particles in increasing the breakdown of starch to reduce the level of sugar in the large intestine and thus reduce fermentation disorders in the cecum. Increasing the effectiveness of some enzymes such as trypsin and peroxidase can last for several weeks instead of several hours when combined with nanomaterial like iron nanoparticles [34], which helps in improving the metabolic efficiency and digestion of the substances ingested in horses. The mechanism of action of nanocomposites in horses can be summarized as shown in Fig. 3 .

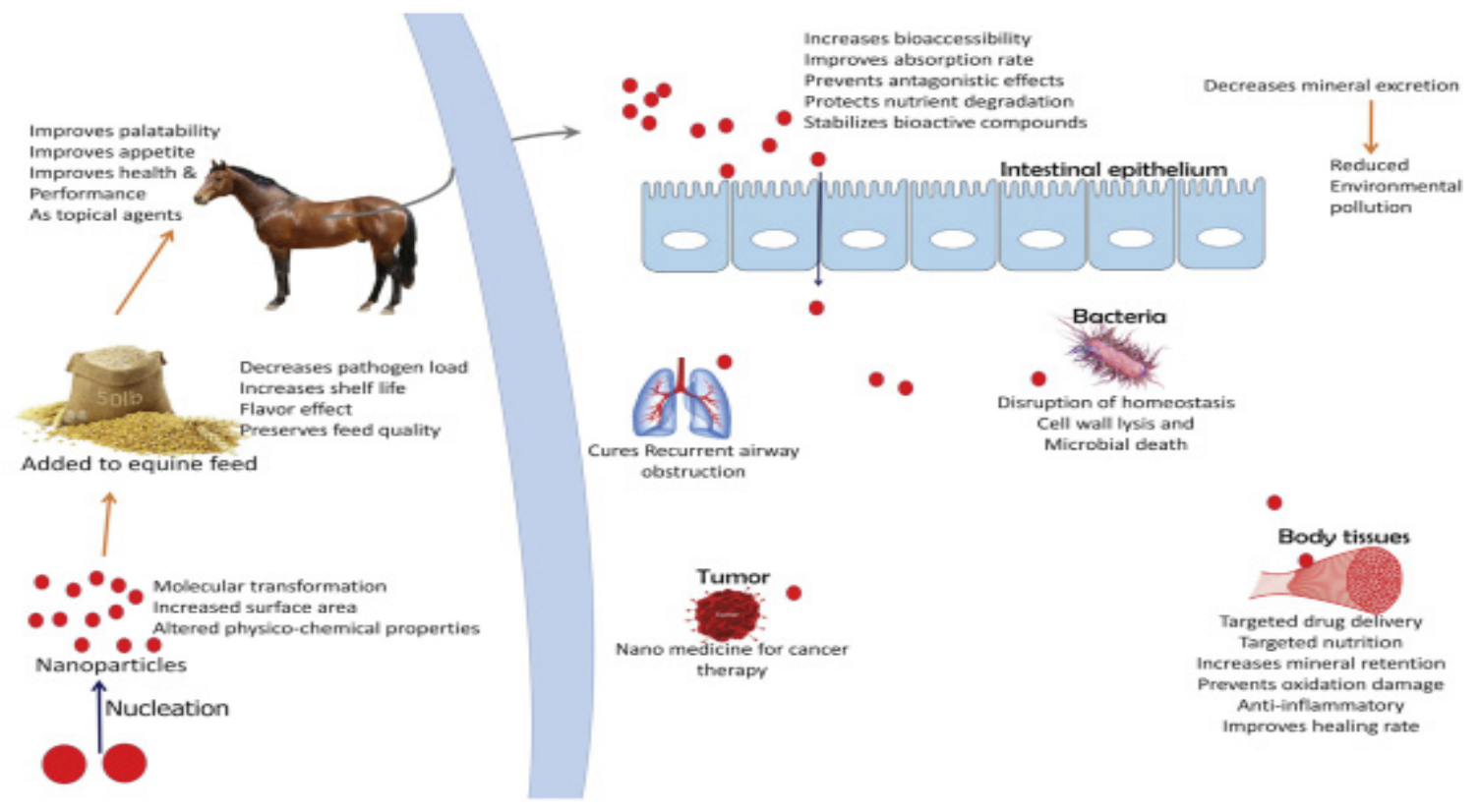

Fig. 3. Nanotechnique in horse nutrition [31].

Egypt. J. Vet. Sci. Vol. 52, No. 3 (2021) 


\section{Conclusion}

We conclude from this article that the nanotechnology mechanism can be applied in the production of nanocomposites that can be used to improve digestion and absorption in farm animals as ingredients or new feed additives while improving the quality of nutrients. Nanotechnology is still in continuous development to this day, with the aim of improving animal production. Studies in this area are still very limited. Nanocomposites should be incorporated into animal nutrition research that could significantly enhance animal growth and production efficiency with minimal risks to consumers. However, a great deal of research is still needed to support the efficacy, primarily the safety of nanotechnology, and the avoidance of any harm to animals, humans, and the surrounding environment.

\section{Acknowledgement}

This review was funded by the College of Veterinary Medicine, University of Mosul, Mosul, Iraq.

\section{Conflict of Interest}

This is a review article, no conflict of interest.

\section{References}

1. Hameed, H.M., Tawfeek, F.K. and Adul-Rhaman, S.Y. Effect of $\beta$-mannanase, Lysolecithin and probiotic on some reproductive performance and hormone profile in female quail. Iraqi Journal of.Iraqi, 34 (1), 87-93(2020).

2. Maty, H.N. and Hassan, A.A. Effect of supplementation of encapsulated organic acid and essential oil Gallant $+^{\circledR}$ on some physiological parameters of Japanese quails. Iraqi. J. Vet. Sci., 34,181-188(2019).

3. Surej Joseph Bunglavan1, A.K., Garg, R.S., Dass and Sameer Shrivastava.Use of nanoparticles as feed additives to improve digestion and absorption in livestock.Livestock Research International., 3, 36-47(2014).

4. Troncarelli, M.Z., Brandão, H.M., Gern, J.C., Guimarães, A.S and Langoni,H. Nanotechnology and Antimicrobials in Veterinary Medicine., 1,543-556(2013).

5. Manuja,A., Kumar, B and Singh, R.K. Nanotechnology developments: opportunities for animal health and production. Nanotechnol. Dev., 2, 4-8(2012).
6. Ravi Kanth Reddy, P., Duvvuru Yasaswini, P. Pandu Ranga Reddy, Mohamed Zeineldin, M.J. Adegbeye and Iqbal Hyder. Applications, challenges, and strategies in the use of nanoparticles as feed additives in equine nutrition. Veterinary World., 13(8), 16851696 (2020). EISSN., 2231-0916

7. Gopi, M., Pearlin, B., Kumar, R.D., Shanmathy, M. and Prabakar, G. Role of nanoparticles inanimaland poultrynutrition: Modesofaction and applications in formulating feed additiv food processing. Int. J. Pharmacol., 13(7),724-731(2017).

8. Wang, C., Zhang, L., Ying, Z., He, J., Zhou, L., Zhang, L., Zhong, X. and Wang, T. Effects of dietary zinc oxidenanoparticles on growth, diarrhea, mineral deposition,intestinal morphology, and barrier of weaned piglets. Biol. Trace Elem. Res., 185(2), 364-374(2018).

9. Marappan Gopi., Beulah Pearlin., Ramasamy Dhinesh Kumar., MuthuvelShanmathy and GovindasamyPrabakar. Role of Nanoparticles in Animal and Poultry Nutrition: Modes of Action and Applications in Formulating Feed Additives and Food Processing.International Journal of Pharmacology., 13(7),724-731(2017).

10. Swain, P.S, Rajendran, D., Rao, S.B., Dominic, G. Preparation and effects of nano mineral particle feeding in livestock: a review. Vet. World, 8, 888891(2015).

11. Mishra, A., Swain, R., Mishra, S., Panda, N., Sethy, K. Growth performance and serum biochemical parameters as affected by nano zinc supplementation in layer chicks. Indian J. Anim. Nutr., 31, 384-388(2014).

12. Rajendran, D. Application of nano minerals in animal production system. Res. J. Biotechnol., 8, 1-3(2013).

13. Yazdani, A., Poorbaghi, S.L. and Habibi H. Dietary Berberis vulgaris extract enhances intestinal mucosa morphology in thebroiler chicken (Gallus gallus). Comp. Clin. Path., 22, 611-615 (2013).

14. Lei, X.J., Ru, Y.J. and Zhang, H.F. Effect of Bacillus amyloliquefaciensbased direct-fed microbials and antibiotic on performance, nutrient digestibility, cecalmicroflora, and intestinal morphology in broiler chickens. J. Appl. Poult. Res., 23,1-8(2014).

Egypt. J. Vet. Sci. Vol. 52, No. 3 (2021) 
15. Ahmadi, F., Ebrahimnezhad, Y., Sis, N.M. and Ghiasi, J. The effects of zinc oxide nanoparticles on performance, digestive organs and serum lipid concentrations in broiler chickens during starterperiod. Int. J. Biosci., 3, 23-29(2013).

16. Hu, C.H., Gu, L.Y., Luan, Z.S. Effects of montmorillonite-zinc oxide hybrid on performance, diarrhea, intestinal permeability and morphology of weanling pigs. Anim. Feed Sci. Technol., 177,108-115(2012).

17. Sultan Ali., Saima Masood., Hafsa Zaneb., Hafiz Faseeh-ur-Rehman., SabiqaaMasood., Muti-ur-Rehman Khan., Sajid Khan Tahir and Habibur Rehman. Supplementation of Zinc Oxide Nanoparticles has Beneficial Effects on Intestinal Morphology in Broiler Chicken. Pakistan Veterinary Journal, 37(13), 1-5 (2017). https://www.researchgate.net/ publication/319481090.ISSN,0253-8318.20747764

18. Duritis, I. and Mugurevics, A.Distribution and Characterization of Goblet Cells in the Large Intestine of Ostriches during the Pre-and PostHatch Period.Anat. Histol. Embryo., 145,457462(2015).

19. Abbasi, S.R., Hashemi, S., Hassani, M. and Ebrahimi. Gastrointestinal Microbial Population Response and Performance of Broiler Chickens Fed with Organic Acids and Silver Nanoparticles Coated on Zeolite under Heat Stress Condition. Iranian Journal of Applied Animal Science., 8 (4) 685-691(2018)

20. Amlan Patraand Melody Lalhriatpuii. Progress and Prospect of Essential Mineral Nanoparticles in Poultry Nutrition and Feeding-A Review. Biological Trace Element Research, 197, 233253(2020).

21. Castillo-Gonzáleza, A.R., Burrola-Barrazab, J.,Domínguez-Viverosb, A and Chávez-Martínezb. Rumen microorganisms and fermentation. Arch. Med. Vet., 46, 349-361(2014).

22. Kingston-Smith, A.H.,Marshall, A.H and Moorby, J.M. Breeding for genetic improvement of forage plants in relation to increasing animal production with reduced environmental footprint. Animal Production, 1,1-10(2012).

23. $\mathrm{Wu}, \mathrm{G}$. Principles of Animal Nutrition. $1^{\text {st }}$ ed. Boca Raton, FL, USA: Taylor \& Francis Group (2018).
24. Hassan Riazi, Javad Rezaei and Yousef Rouzbehan. Effect of supplementary nano-ZnO on in vitro ruminal fermentation, methane release, antioxidants, and microbial biomass. Turk. J. Vet. Anim. Sci., 43, 737-746(2019)

25. Sarker, N.C., Keomanivong, F., Borhan, M., Rahman, S. andSwanson,K.In vitro evaluation of nano zinc oxide $(\mathrm{nZnO})$ on mitigation of gaseous emissions. Journal of Animal Science and Technology, 60(1), 27-32(2018).

26. Adegbeye, M.J., Elghandour, M.M., Barbabosa-Pliego, A., Monroy, J.C. and Mellado, M. Nanoparticles in equine nutrition: mechanism of action and application as feed additives. Journal of Equine Veterinary Science, 78 (1), 2937(2019).

27. Bai, D.P., Lin, X.Y., Huang, Y.F. and Zhang, X.F. Theranostics aspects of various nanoparticles in veterinary medicine. Int. J. Mol. Sci.,19:1e32(2018).

28. Xie, Y., Liu, Y., Yang, J., Liu, Y., Hu, F. and Zhu, K. Gold nanoclusters for targeting methicillinresistant Staphylococcus aureus in vivo. Angew. Chem. Int. Ed. Engl., 57(15), 3958-3962 (2018).

29. Mallicote, M., House, A.M. and Sanchez, L.C.A review of foal diarrhea from birth to weaning. Equine Vet. Educ., 24(4), 206-214(2012).

30. Moyosore, J., Adegbeye, A., Mona, M.M.Y., Elghandour, B., Alberto Barbabosa-Pliego, B., Jose CedilloMonroy, C., Miguel Mellado, D., Poonooru Ravi Kanth Reddy, E., Abdelfattah, Z.M. and Salem,B.Nanoparticles in Equine Nutrition: Mechanism of Action and Application as Feed Additives. Journal of Equine Veterinary Science, 78,29e37(2019)

31. Moyosore, J., Adegbeye, A., Mona, M.M.Y., Elghandour, B., Alberto Barbabosa-Pliego, B., Jose CedilloMonroy, C., Miguel Mellado, D., Poonooru Ravi Kanth Reddy, E., Abdelfattah, Z.M. and Salem,B.Nanoparticles in Equine Nutrition: Mechanism of Action and Application as Feed Additives. Journal of Equine Veterinary Science, $78,29 \mathrm{e} 37(2019)$

32. El Sabry, M.I., McMillin, K.W and Sabliov, C.M. Nanotechnology considerations for poultry and livestock production systems e a review. Ann. Anim. Sci.,18, 319e34(2018). 
33. Saware, K., Aurade, R.M., Jayanthi, P.D.K. and Abbaraju, V. Modulatory effect of citratereduced gold and biosynthesized silver nanoparticles on a-Amylase activity. J. Nanoparticles., 2(1),9 pages (2015). Article ID 829718, https://doi. org/10.1155/2015/829718

34. Deka, J., Paul, A. and Chattopadhyay, A. Modulating enzymatic activity in the presence of gold nanoparticles. RSC $A d v$., 2,4736e45(2012).

\title{
الاور الفسلجي لتقنية النانوتكنلوجي في تغذية الحيوانات والدواجن : مقالة بحثية \\ هديل محمد حميا \\ فرع الفسلجة و الكيمياء الحياتية والادوية , كلية الطب البيطري , جامعة الموصل , الموصل , العراق
}

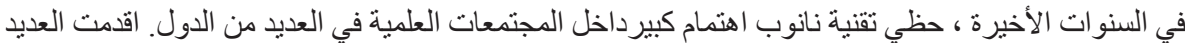

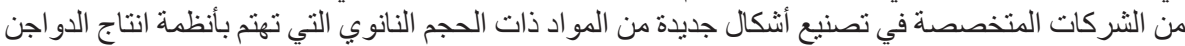

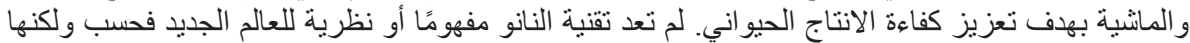

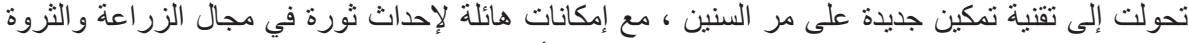

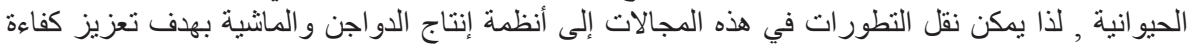

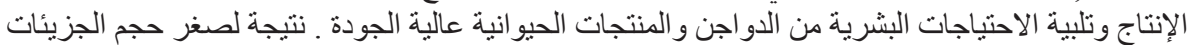

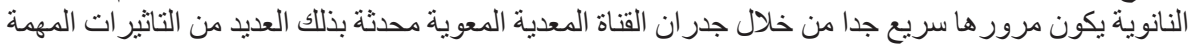

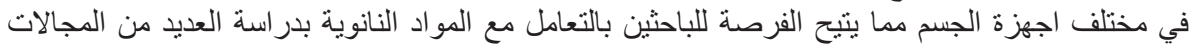

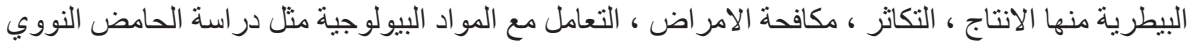

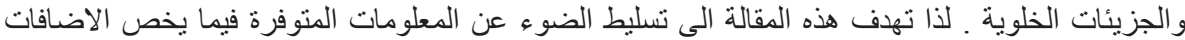

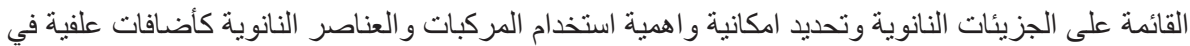
علائق الحيو انات .
\end{abstract}

الكلمات المفتاحية: تقنية النانو ، دو اجن ، الاضافات العلفية ، انتاج ، الماثية ، الفسلجة. 